\title{
Porphyrinoid macrocycles: A cornucopia of novel chromophores
}

\author{
Emanuel Vogel \\ Institut für Organische Chemie der Universität zu Köln \\ Greinstrasse 4, 50939 Köln, Germany
}

\begin{abstract}
The porphyrins, due to their role as "Pigments of Life" (A. Battersby) to be regarded as functional dyes par excellence, have developed into an interdisciplinary area of research comprising chemistry, the biosciences, medicine and even material science. Guided by the [18]annulene model of porphyrin, which implies the presence of a $(4 n+2) \pi$ conjugation pathway in the tetrapyrrolic macrocycle, we recently embarked on a systematic exploration of novel porphyrinoid chromophores. As a result of these efforts, a comucopia of potential functional dyes and pigments - such as porphyrin isomers, dicationic tetraoxa-, tetrathia- and tetraselenaporphyrins, corrole isomers and, most recently, chiral cyclooctapyrroles - have been brought to light. In this report the tetraand octapyrrolic porphyrinoid chromophores have been singled out for discussion.
\end{abstract}

\section{PORPHYRIN ISOMERS}

The discovery of porphycene 6 at the Cologne laboratory in 1986 has opened up a new avenue of research in porphyrin chemistry having great potential: the porphyrin isomers (1-4). Although such tetrapyrrolic macrocycles are among the most obvious porphyrin structural variants, surprisingly, not even a hint as to their possible existence could be found in the chemical literature prior to the synthesis of 6 . As revealed by pertinent methods of investigation, porphycenes qualify as porphyrin-like in many of their physical and chemical properties. Additionally, their brilliant colors and general optical behavior - $\underline{6}$ and most of its derivatives are strongly fluorescent blue pigments exhibiting remarkable photostability - make these compounds a chemist's delight.

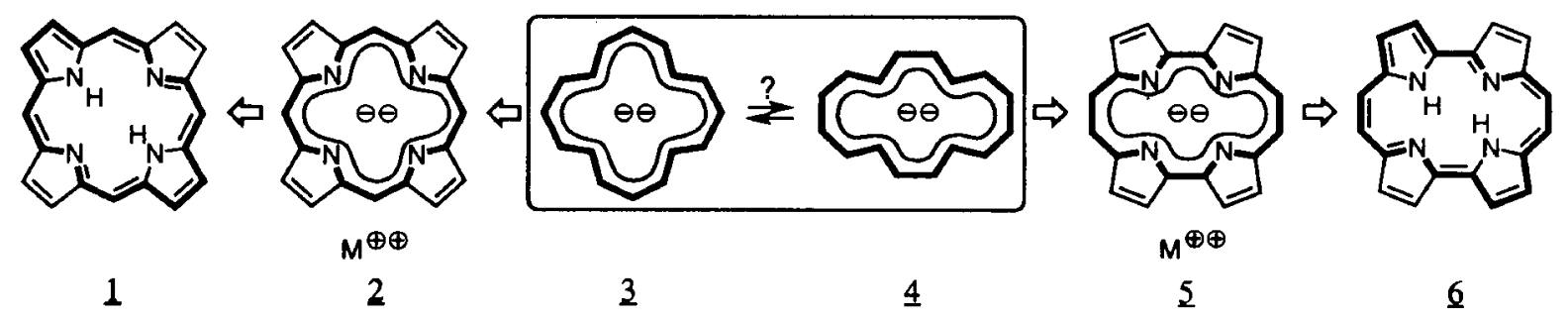

It is of interest to note that the idea of porphycene originated from investigations in [16]annulene chemistry, i.e., from our admittedly unsuccessful search for the presumed equilibrium between the well-known $18 \pi$ [16]annulene dianion 3 and its as yet hypothetical configurational isomer 4 . Having been aware of the structural and electronic relationship that 3 bears to the dianion 2 of porphyrin (as its magnesium complex) it occurred to us on tinkering with this equilibrium that $\underline{4}$ is analogously related to dianion $\underline{5}$, an isomer of $\underline{2}$. To get to 6 itself, dianion 5 needs only to be protonated.

In more simple terms, 6 can be envisaged to derive from 1 by a mere reorganization of the pyrrole and methine moities of the latter in such a way as to maintain an $\mathrm{N}_{4}$ coordination site. This conceptual approach to porphycene $\underline{6}$ leads to the realization that $\underline{6}$ is but one member of a family of no less than seven porphyrin isomers - compounds 6 - 12 - having an $\mathrm{N}_{4}$-core and one or two cisoid $\mathrm{C} \cdots \mathrm{CH} \cdots \mathrm{CH} \cdots \mathrm{C}$-units (arene fragments) as common features (5). A compilation of the isomers, listed according to their thermodynamic 
TABLE 1. The isomers of porphyrin 1 with an $\mathrm{N}_{4}$ coordination site, [18]porphyrin- $(\because \because \cdot) 6-12$, and their relative energies of formation $(\mathrm{kcal} / \mathrm{mol})$ calculated with 1 as the reference.

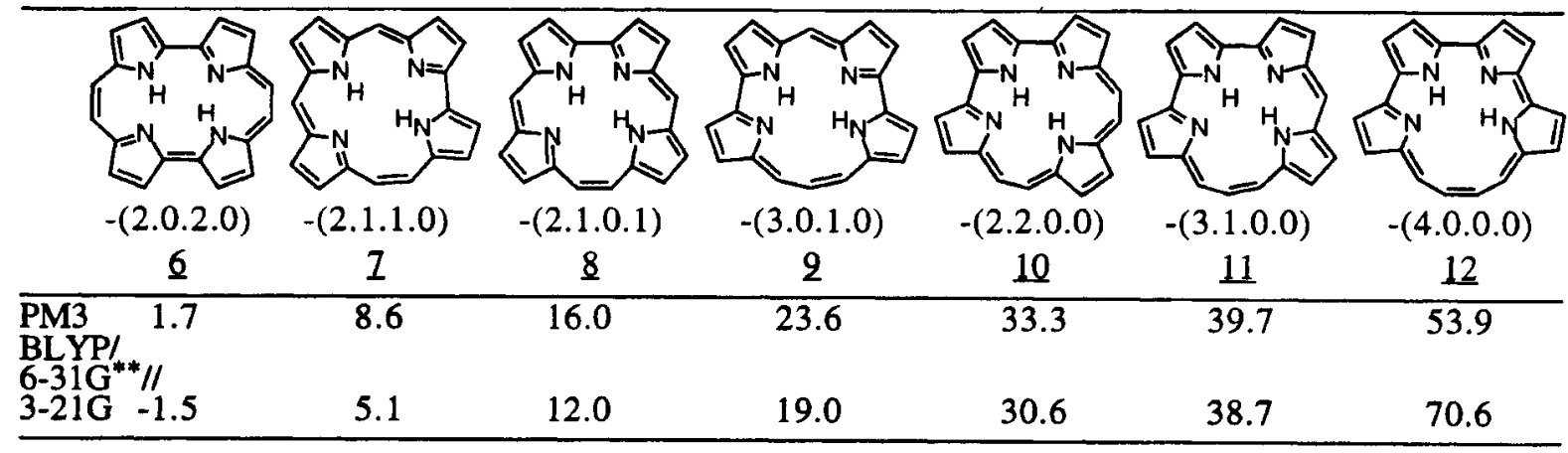

stability, is given in Table 1. In order to assess whether the as yet unknown isomers 7-12 will resemble 1 , the relative energies of $6-12$ - with 1 as the reference - were calculated employing the PM3 and BLYP/6-31G**//3-21G methods (6). From these calculations the following may be deduced: 1) Porphycene matches porphyrin in energy although it is slightly strained; presumably, the strong $\mathbf{N}-\mathbf{H} \cdots \mathbf{N}$ hydrogen bonds present in this isomer keep the energetic balance. 2) The relative energies rise considerably as one goes from 1/6 to 12; however, the increase remains modest for 7 and 8 . 3) Planarity of the ring skeleton applies to all of the isomers except 12. - Based on the above considerations, among the isomers still awaiting synthesis, at least 7 and 8 promise to be endowed with porphyrin-like properties.<smiles>[R]c1cc(-c2cc([R])c(-c3cc([R])c(C=O)[nH]3)[nH]2)[nH]c1C=O</smiles>

13

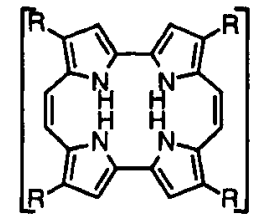

14

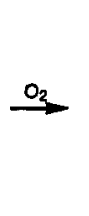

16

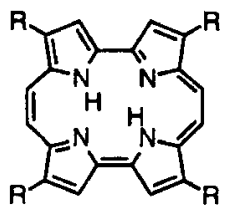

$$
\begin{array}{cl}
6 & \mathrm{R}=\mathrm{H} \\
17 & \mathrm{R}=\mathrm{C}_{3} \mathrm{H}_{7}
\end{array}
$$

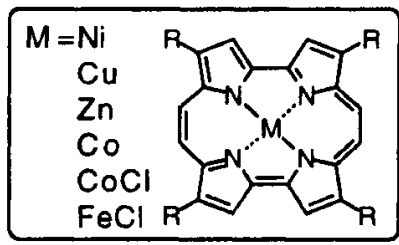

$18 \quad \mathrm{R}=\mathrm{C}_{3} \mathrm{H}_{7}$

The synthesis of porphyrin isomers poses a challenge since it is obvious that methodology commonly used in making porphyrins, such as biomimetic routes, would hardly provide access to these possibly nonnatural target molecules. Viewing the generation of the formal double bond(s) - common to all of the isomers - as the key step of the synthesis, we reasoned that these molecules might best be approached by reductive carbonyl coupling of appropriate open-chain di- or tetrapyrrolic $\alpha, \omega$-dialdehydes (or diketones). Indeed, the McMurry coupling reaction, hitherto alien to porphyrin chemistry, has thus far proved to be the method of choice for the preparation of porphyrin isomers.

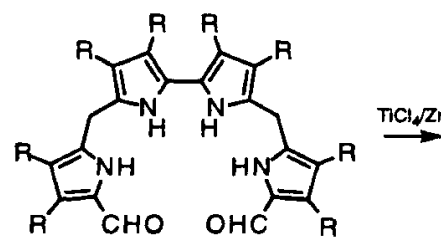

19

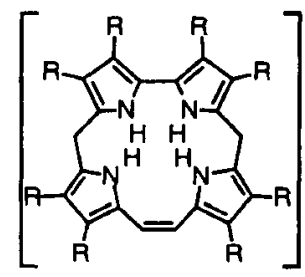

20
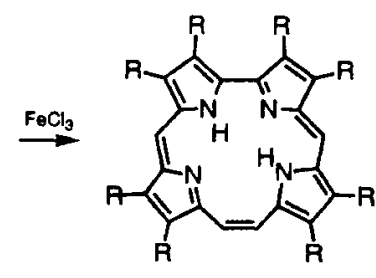

21

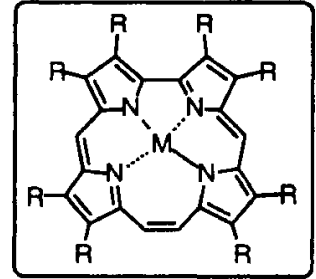

22

(under investigation)

In the case of porphycene synthesis - which got all of the work in the field started - Woodward and Dolphin's 5,5'-diformyl-2,2'-bipyrrole 13 appeared to be an ideal building block. In accord herewith, reductive carbonyl coupling of 13 by means of titanium tetrachloride/zinc directly afforded porphycene 6 in low yield as the only non-polymeric product. Remarkably, the obligate intermediate of the reduction, the $N, N$-dihydroporphycene 14, an NH-bridged [16]annulene, turned out to be so prone to oxidation that it 
escaped detection even when oxygen was excluded from the reaction medium. Embarking from the appropriate bipyrrole dialdehydes or diketones, McMurry coupling has since allowed the preparation of an entire host of alkyl- and aryl-substituted porphycenes (yields as high as $30 \%$ ). Among these, the symmetrical 2,7,12,17-tetrapropylporphycene 17 (from 15 via 16) stands out, for its favorable solubility properties have made it the "workhorse" in developing porphycene chemistry.<smiles>[R]c1c(Cc2[nH]c(C=O)c(Cc3[nH]c(C=O)c(C(=O)O)c3[R])c2[R])[nH]c(C(=O)OO)c1[R]</smiles>

23

24<smiles>[R]C1=C(C)C(=Cc2c(Cc3[nH]c(CO)c([R])c3CC)[nH]c(CC)c2[R])N=C1c1[nH]c(C)c([R])c1CC</smiles>

25

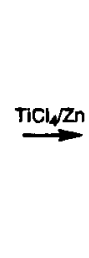

not isolated

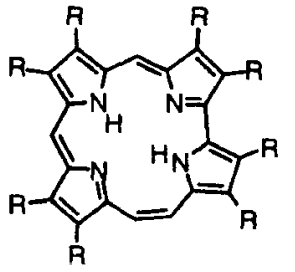

26

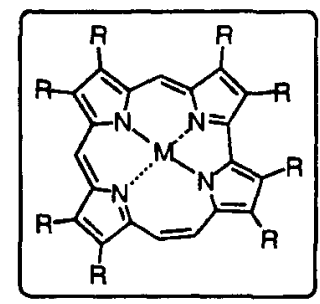

$\mathrm{R}=\mathrm{C}_{2} \mathrm{H}_{5}$

(under investigation)

The synthesis of porphycene inspired the idea that other porphyrin isomers, in particular [18]porphyrin(2.1.1.0) 7 (hemiporphycene) and [18]porphyrin-(2.1.0.1) 8 (corrphycene), might be made. Recently, this expectation has been borne out in a collaborative effort between J.L. Sessler at the University of Texas in Austin and the Cologne group, which resulted in successful approaches to both octaethylcorrphycene 21 (2a,b) and octaethylhemiporphycene 26 (3b) by means of reductive coupling employing the tetrapyrrolic $\alpha, \omega$-dialdehydes 19 and 25 (generated in situ from 23 and 24 ), respectively, as strategic precursors. In contrast to $14 / 16$ in the porphycene series, the primary products of coupling of 19 (i.e., 20 ) and of its counterpart in the hemiporphycene series (not shown here) do not undergo spontaneous oxidation. Rather, these intermediates need to be treated with iron(III) chloride or other oxidizing agents in order to effect final conversion into the respective porphyrin isomers. Attesting to the interest porphyrin isomers have attracted, further syntheses of corrphycenes (2c,d) and hemiporphycenes ( $3 a$ ) have almost simultaneously been described.

In our previous studies on porphycene, encompassing the elaboration of its rich coordination chemistry, we have shown that this tetrapyrrolic macrocycle and its metal complexes (e.g., 18) (7) bear a surprisingly close relationship to porphyrin and metalloporphyrins, respectively. As evidenced by very recent findings, the same is true for the new isomers corrphycene 21 and hemiporphycene 26 . Needless to say, the availability of porphyrin and three of its isomers invites a wide range of comparative investigations (covering physical, chemical, medicinal and even material science aspects) on this intriguing set of compounds.

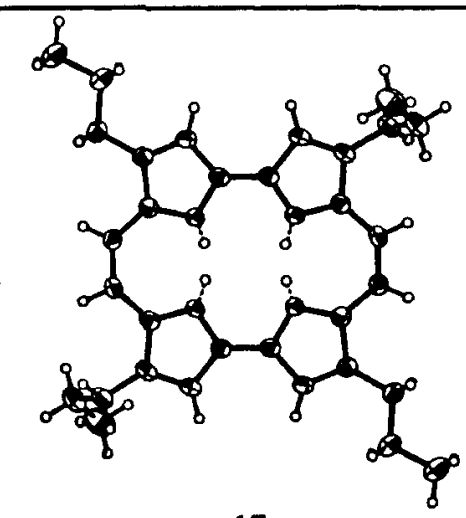

17

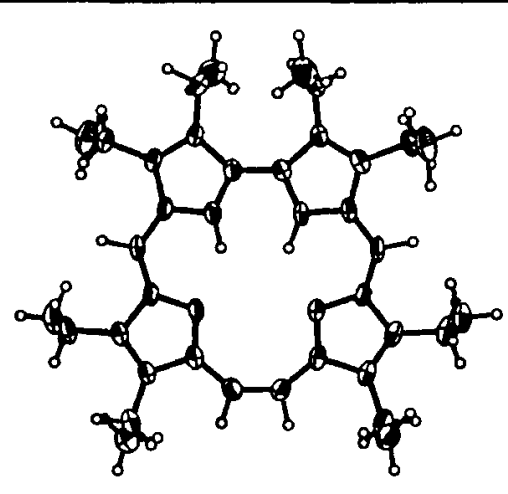

$\underline{21}$

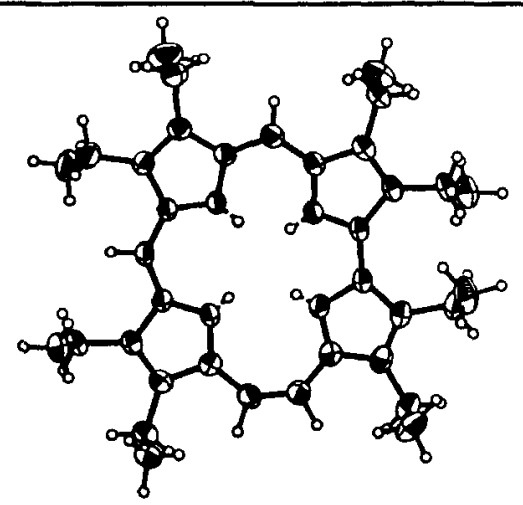

$\underline{26}$

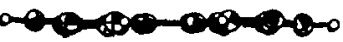

Fig.1 Single crystal X-ray structures of tetrapropylporphycene 17 , octaethylcorrphycene 21 and octaethylhemiporphycene 26 (top and side view; substituents have been omitted from the latter). 
The basis for such investigations is laid by the structural finding that the three isomers, like porphyrin, are planar aromatic species (see Fig. 1). In each of the isomers, aromaticity manifests itself particularly clearly in the observation that the $\mathrm{CC}$ bunds of the $\mathrm{C}_{4}$ unit containing the formal double bond do not alternate in length but are typical benzenoid aromatic bonds (this analogy to the acenes was responsible for the ending "cene" in the names given to these isomers).

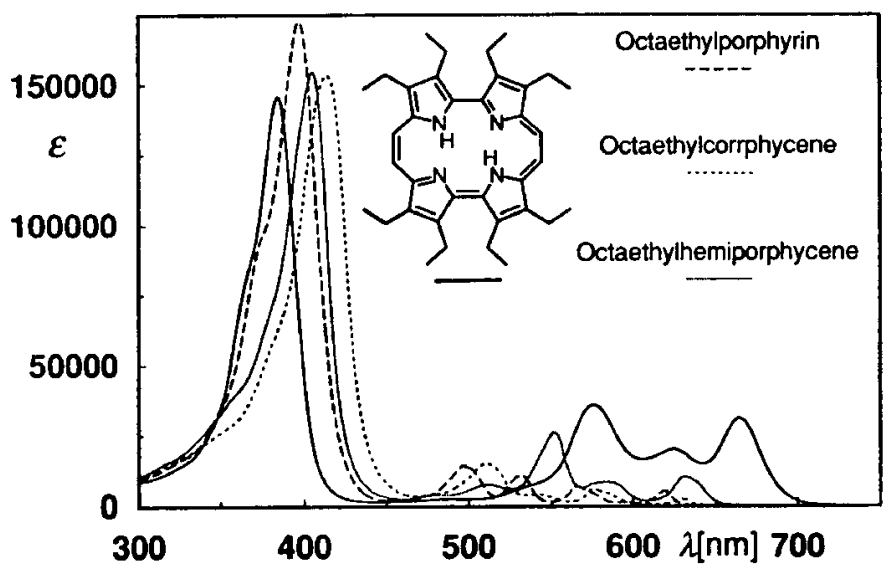

Fig. 2 UV/Vis spectra of octaethylporphyrin, octaethylporphycene, octaethylcorrphycene 21 and octaethylhemiporphycene 26 (in dichlormethane).
The similarities between porphyrin and its isomers found to exist with respect to molecular structure extend, as anticipated, to the electronic structure of these compounds. The UV/Vis spectra of all of the isomers (as octaethyl derivatives), shown together with the spectrum of octaethylporphyrin in Fig. 2, are distinctly porphyrin-type in that they exhibit the characteristic Soret band in the $400 \mathrm{~nm}$ region as well as a set of $Q$ bands at longer wavelengths.

Qualitatively, the UV/Vis spectrum of porphycene differs from those of its congeners in that it possesses a relatively strong $Q$ band absorption at $560-680 \mathrm{~nm}$, i.e., in the region where blood and body tissue are fairly translucent. This absorption pattern in conjunction with other photophysical properties of the compound, such as its stability towards photooxidation, its high quantum yields of fluorescence and singlet oxygen sensitation (8), render porphycenes promising agents for the detection and photodynamic therapy (PDT) of tumors. In light of favorable toxicology tests on porphycenes and the potential these compounds might have not only in PDT but also in the treatment of diverse dermatological diseases, a chemical company (Cytopharm, Inc., Menlo Park, CA) has been founded with the intention of developing this type of porphyrin isomer with regard to medicinal applications (9).

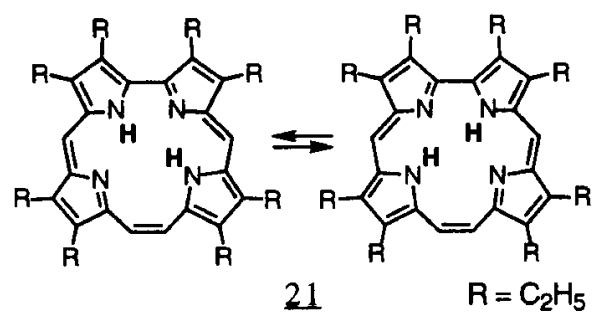

Fig. 3 Degenerate NH-tautomerism in octaethylcorrphycene 21 .
The observed similarities in the ${ }^{1} \mathrm{H}$ NMR spectra of porphyrin and its three known isomers with regard to ring current effects provides additional strong evidence in support of the contention that one is dealing with a set of closely related compounds. Moreover, NMR spectroscopy has allowed the evaluation of the NH-tautomerism existing in these molecules. A case in point is the ${ }^{1} \mathrm{H}$ NMR spectrum of octaethylcorrphycene 21 . Here, from an observed temperature dependence it can be derived that 21 undergoes a degenerate NH shift (Fig. 3) rapid on the NMR time scale $\left(\Delta G^{\#}=8.3 \mathrm{kcal} / \mathrm{mol}\right.$ as compared to $10-15 \mathrm{kcal} / \mathrm{mol}$ in porphyrins).

Taking into account the dominant role metalloporphyrins play in porphyrin chemistry, chemical interest in porphyrin isomers focuses on metal complexation and its ramifications. Although the isomers exhibit geometries of the $\mathrm{N}_{4}$ coordination site noticeably deviating from the ideal square-shape of the porphyrin core - porphycene: rectangular, corrphycene: pronouncedly trapezoid, hemiporphycene: unsymmetrical - they all qualify as versatile ligands. Metalloporphycenes, -corrphycenes and -hemiporphycenes can therefore safely be predicted to complement metalloporphyrins in many ways. 


\section{CORROLE AND ISOMERS}

Corrole 28, regarded as a "Contracted Porphyrin", owes its importance as a porphyrinoid pigment to the close structural relationship it bears to corrin, the ring system of vitamin $B_{12}$. First synthesized by A.W. Johnson (as octaalkyl derivatives) (10), 28 is potentially trianionic. However, like porphyrin, corrole features an $18 \pi$-electron conjugation pathway.

TABLE 2. Corrole 28 and its isomers with an $\mathrm{N}_{4}$ coordination site, [18]corrole-( $\because \because)$ 29-31.

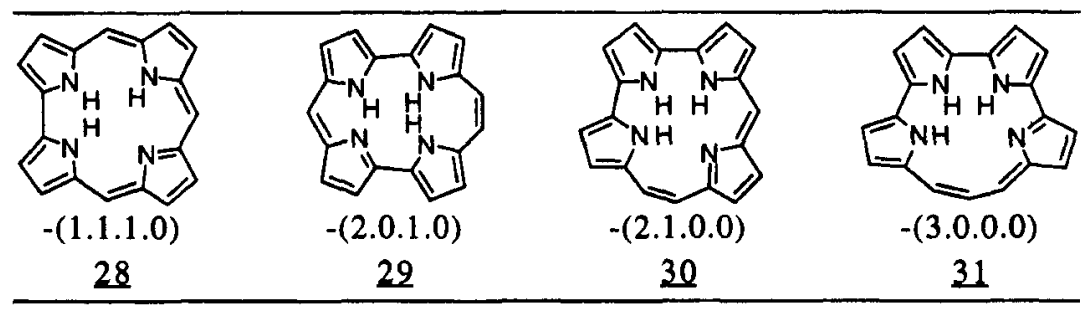

In view of the history of porphyrin isomers it is hardly surprising that the possible existence of corrole isomers has likewise not been considered previously. As shown in Table 2, three isomers of 28 (i.e., compounds 29-31) are theoretically feasible. Retrosynthetic analysis as well as thermodynamic considerations led us to select corrole-(2.0.1.0) 29 (isocorrole) as the prime target for synthesis in this domain.

Capitalizing on experience gained in the synthesis of porphyrin isomers, we were able to prepare octaethylisocorrole $\underline{34}$ starting from the linear tetrapyrrole 32 by a sequence involving reductive carbonyl coupling of the tetrapyrrolic $\alpha, \omega$-dialdehyde 33 as the crucial step (11). In accord with expectations, 34 is similar to octaethylcorrole in structural, spectral and chemical respects.

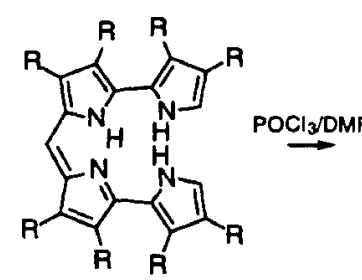

32

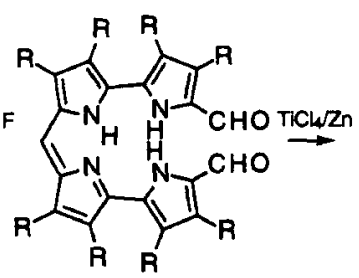

33

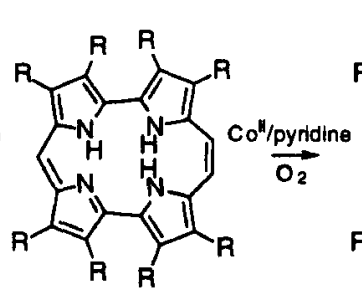

34

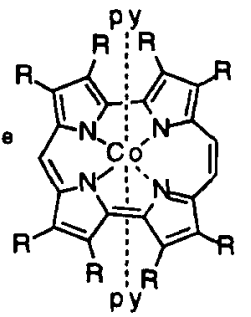

$\underline{35}$
$\mathrm{R}=\mathrm{C}_{2} \mathrm{H}_{5}$

The finding that the octaethylisocorrole $\underline{34}$ readily forms the cobalt(III) complex $\underline{35}$ whereas it failed to afford a defined iron(III) complex on treatment with iron(III) transfer agents prompted us to reinvestigate the alleged isolation of iron(III) corrole complexes. In pursuing this side-line we made the striking discovery that corroles are capable of stabilizing iron in a formal tetravalent oxidation state. Specifically, on reaction of octaethylcorrole with nonacarbonyldiiron, the iron(III) corrole presumed to be formed initially was not isolated since it underwent spontaneous oxidation by air to give $\mu$-oxo-diiron(IV) octaethylcorrole (12). This binuclear complex could in turn be converted into a variety of mononuclear iron(IV) octaethylcorrole complexes.

\section{CYCLOOCTAPYRROLES - AN OUTLOOK}

Our exploratory studies on corrole/corrole isomers had yet another unforeseen result in that they brought to light the first examples of octapyrrolic macrocycles, a hitherto dormant type of "Expanded Porphyrins". To our knowledge, the only polypyrrolic macrocycle containing more than six pyrrole rings presently known is Sessler's turcasarin (13), a cyclodecapyrrole described recently. On reinvestigation of the McDonald condensation between 5,5'-diformyl-2,2'-bipyrrole 36 and dipyrromethane dicarboxylic acid 37 - a possible route to corroles pursued unsuccessfully previously (14) - we found that in fact two molecules each of 36 
and 37 cyclocondensed to afford, after spontaneous oxidation of the supposed intermediate 38 , the fully conjugated cyclooctapyrrole 39 . Steric constraints do not allow this molecule to exist in a planar conformation such as that represented by $39 \mathrm{a}$. Instead, as inferred from an inspection of molecular models,

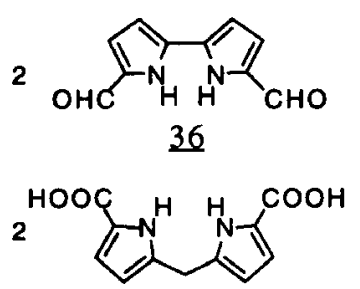

37

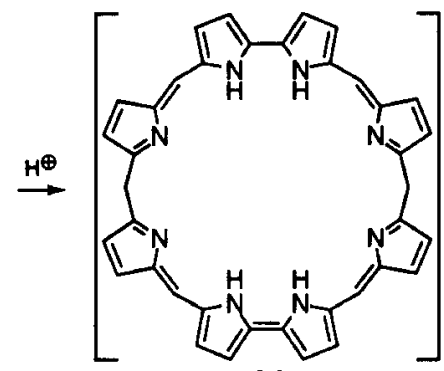

38

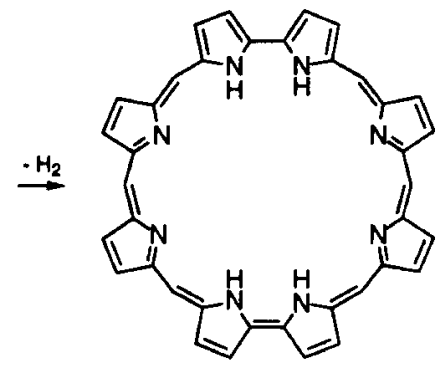

a

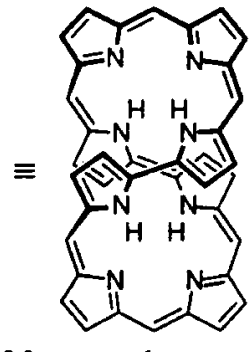

b

all $\beta$-pyrrolic positions ethyl substituted

and, indeed, borne out by an X-ray crystallographic analysis, 39 adopts the twisted "Figure Eight" conformation $39 \mathrm{~b}$ which is chiral and thus offers the chance that 39 might be separable into enantiomers. Compound 39 appears to herald the emergence of an entire class of octapyrrolic macrocycles. Ongoing work at this laboratory has very recently provided further examples (15) to show that, in cyclocondensation reactions of pyrrolic building blocks, the formation of cyclooctapyrroles may in fact be favored over that of conventional cyclotetrapyrroles, if access to the latter is suppressed for mechanistic or conformational reasons.

\section{REFERENCES}

1. Porphycenes: E. Vogel, M. Köcher, H. Schmickler, J. Lex, Angew.Chem.Int.Ed.Engl. 25, 257 (1986); E. Vogel, Pure Appl.Chem. 62, 557 (1990); ibid. 65, 143 (1993); E. Vogel, P. Koch, X.-L. Hou, J. Lex, M. Lausmann, M. Kisters, M.A. Aukauloo, P. Richard, R. Guilard, Angew.Chem.Int.Ed.Engl. 32, 1600 (1993).

2. Corrphycenes: a) J.L. Sessler, E.A. Brucker, S.J. Weghorn, M. Kisters, M. Schäfer, J. Lex, E. Vogel, Angew.Chem.Int.Ed.Engl. 33, 2308 (1994); b) J.L. Sessler, Angew.Chem.Int.Ed.Engl. 33, 1348 (1994); c) M. Aukauloo, R. Guilard, New J.Chem. 18, 1205 (1994); d) H. Falk, Q.-Q. Chen, Monatsh.Chem. (in press).

3. Hemizorphycenes: a) H.J. Callot, A. Roher, T. Tschamber, B. Metz, NewJ.Chem. 19, 155 (1995); b) E. Vogel, M. Bröring, J. Lex, S.J. Weghorn, J.L. Sessler (publication in preparation).

4. Inverted Porphurins: H. Furata, T. Asano, T. Ogawa, J.Am.Chem.Soc. 116, 767 (1994); P.J. Chmielewski, L. Latos-Grazynski, K. Rachlewicz, T. Glowiak, Angew.Chem.Int.Ed.Engl. 33, 779 (1994).

5. J. Waluk, J. Michl, J.Org.Chem. 56, 2729 (1991).

6. E. Vogel, M. Bröring, J. Fink, D. Rosen, H. Schmickler, J. Lex, K.W.K. Chan, Y.-D. Wu, D. Plattner, K.N. Houk, Angew. Chem.Int.Ed.Engl. (in press).

7. J.P. Gisselbrecht, M. Gross, M. Köcher, M. Lausmann, E. Vogel, J.Am.Chem.Soc. 112, 8618 (1990); W.A. Oertling, W. Wu, J.J. López-Garriga, Y. Kim, C.K. Chang, J.Am.Chem.Soc. 113, 127 (1991); Z.-Y. Li, J.-S. Huang, C.-M. Che, C.K. Chang, Inorg.Chem. 31, 2670 (1992); K.M. Kadish, E. Van Caemelbecke, P.Boulas, F. D'Souza, E. Vogel, M. Kisters, C.J. Medforth, K.M. Smith, Inorg.Chem. 32, 4177 (1993).

8. P.F. Aramendia, R.W. Redmond, S. Nonell, W. Schuster, S.E. Braslavsky, K. Schaffner, E. Vogel, Photochem. and Photobiol. 44, 555 (1986).

9. K. Schaffner, E. Vogel, G. Jori in E.G. Jung, M.F. Holick (Eds.), Biologic Effects of Light, p. 312, Walter de Gruyter, Berlin, New York (1994).

10. A.W. Johnson in K.M. Smith (Ed.), Porphyrins and Metalloporphyrins, p. 729, Elsevier, Amsterdam (1975).

11. E. Vogel, B. Binsack, H. Bormann, Y. Hellwig, J. Lex (publication in preparation).

12. E. Vogel, S. Will, A. Schulze Tilling, L. Neumann, J. Lex, E. Bill, A.X. Trautwein, K. Wieghardt, Angew.Chem.Int.Ed.Engl. 33, 731 (1994).

13. J.L. Sessler, S.J. Weghorn, V. Lynch, M.R. Johnson, Angew.Chem.Int.Ed.Engl. 33, 1509 (1994); for a review on Expanded Porphyrins, see: J.L. Sessler, A.K. Burrell, Top.Curr.Chem. 161, 177 (1992).

14. M. Conlon, A.W. Johnson, W.R. Overend, D. Rajapaksa, C.M. Elson, J.Chem.Soc.,Perkinl 2281 (1973).

15. M. Bröring, J. Jendrny, L. Zander, H. Schmickler, J. Lex, Y.-D. Wu, K.N. Houk, E. Vogel, Angew.Chem.Int.Ed.Engl. (in press). 